\title{
ANTIOXIDANT AND QUALITY ASSESSMENT OF NUGGETS PREPARED FROM BROILER BREAST MEAT REARED ON NATURAL ANTIOXIDANT FROM CITRUS WASTE
}

\author{
FAIZ, F. $^{1 *}$ - WALI, A. ${ }^{1}-$ HuSSAIN, A. ${ }^{1}-$ RAZZAQ, A. ${ }^{2}-$ ARSHAD, M. ${ }^{1}-$ MANZOOR, H. M. I. ${ }^{1}-$ \\ KHAN, S. S. ${ }^{1}$ \\ ${ }^{I}$ Department of Agriculture and Food Technology, Karakoram International University, Gilgit, \\ Pakistan \\ ${ }^{2}$ Department of Biological Sciences, Karakoram International University, Gilgit, Pakistan \\ ${ }^{*}$ Corresponding author \\ e-mail:dr.asifwali@kiu.edu.pk \\ (Received 22 $2^{\text {nd }}$ May 2019; accepted $25^{\text {th }}$ Oct 2019)
}

\begin{abstract}
Citrus is an important fruit produced in the Pakistan. The peel and waste of citrus after juice extraction is mostly wasted which contain important antioxidants and polyphenols. In current study citrus waste after juice extraction was utilized in the production of broiler meat as a feed ingredient, which have positive effects on antioxidant level of the meat. Chicken breast nuggets were prepared from that meat resulting in positive effect on Thiobarbituric acid reactive substances (TBARS) and 2,2-diphenyl-1picrylhydrazy (DDPH) activity of the nuggets. The $\mathrm{pH}$ of the nuggets reduced as the citrus waste supplementation in the feed of the broilers increased, color $\mathrm{L}^{*}$ and $\mathrm{b}^{*}$ values of the nuggets were reduced, and color $\mathrm{a}^{*}$ value was increased as the citrus waste supplementation in the feed of the broilers increased. Texture and water holding capacity of the nuggets have significant effect due to interaction effect of storage and treatments.
\end{abstract}

Keywords: color, meat, nuggets, nutrition, storage, texture, water activity

\section{Introduction}

Chicken meat and its products are used worldwide due to many nutritionally important components which are good for human health i.e., low lipid contents and higher amount of polyunsaturated fatty acids, which are higher than that in any red meat (Jittrepotch et al., 2006). The major cause of deterioration of chicken meat and meat product is oxidation, especially autoxidation because of higher amount of polyunsaturated fatty acids in the meat of chicken which caused in the quality deterioration and off flavor, which can lead to serious health problems (Mohamed et al., 2008). Lipid oxidation in the meat causes undesirable changes by oxidizing fats enzymatically and non-enzymatically. Autoxidation is a chain reaction and causes the meat to deteriorate (Cheng, 2016). The control or minimizing the effect of oxidation is of greater interest for food industry. Oxidation of fats in the meat can be controlled by many strategies including animal dietary supplementation, processing, special packaging and use of antioxidants (Amaral et al., 2018). Because of oxidation problems in meat and meat products the trend of using synthetic antioxidants in broiler meat and meat products is increasing and possibility of toxicity of synthetic antioxidants is a concern for consumers using these products (Prasetyo et al., 2008).

The antioxidant potential of broiler meat and its meat products can be enhanced by feeding broilers with natural antioxidants in feed like alpha-tocopheryl acetate and alphalipoic acid (Sohaib et al., 2012). Alpha tocopherol acetate is effective antioxidant in 
breaking of chain reactions of the oxidation of fats in foods (Miller et al., 2005). Arshad et al. (2011) working on vitamin E supplementation in feed of broiler meat observed that vitamin $\mathrm{E}$ as a source of natural antioxidant is effective in reducing oxidation of meat and meat products more than the control treatments. Kumar and Tanwar (2010) added ground mustard in the chicken meat nuggets and found that the treatments having mustard have greater potential of antioxidants and TBARS value of the treatments, with ground mustard have enhanced antioxidant potential as compared to treatment which were made without ground mustard. Citrus waste as a feed for different animals have studied and proven effective in enhancing antioxidant levels of animals and cost of production also reduced as citrus waste substituted the costly ingredients of feed.

Agricultural wastes including fruit wastes i.e. banana peel, citrus rind etc. are biodegradable and polluting agents for environment if not recycled and reused. But research has explored the importance of this waste material as source of nutrients for plants, animals and birds. Hence, fruit wastes are processed and utilized not only as supplements in food commodities but also as source of nutrients for plants (Arshad et al., 2018).

In the current study the broiler meat was produced using citrus waste supplementation as a feed ingredient. Meat produced from the citrus supplemented waste was incorporated in nuggets and observed for antioxidant and quality profile with objectives to enhance antioxidant profile of chicken meat products and to observe effect of natural antioxidants from broiler meat on storage properties of the nuggets.

\section{Material and methods}

The broiler birds of genus Gallus Domesticus were reared with experimental feed in the Research Farm of Institute of Animal Nutrition in University of Agriculture Faisalabad, Pakistan. Total of 225 birds were used in the study with 15 birds in each treatment. There were three replications of each treatment. The feed of broiler was made with the addition of citrus waste at five different proportions of citrus waste i.e., $0 \%, 2.5 \%$, $5 \%, 7.5 \%$ and $10 \%$ using substitutional method and are indicated as $\mathrm{MN}_{0}, \mathrm{MN}_{2.5}, \mathrm{MN}_{5}$, $\mathrm{MN}_{7.5}$, and $\mathrm{MN}_{10}$, respectively. The birds were reared for 42 days with standard conditions of food, water, and other environmental conditions. The temperature at the farm was maintained as $25-30^{\circ} \mathrm{C}$ with regular supply of water. Lightning was provided for at least 12 hours a day. After 42 days, birds were slaughtered and the breast meat of the broiler of different treatments was used for the preparation of meat nuggets.

\section{Formulation for broiler meat nuggets}

Five treatments of nuggets made with different chicken meat were fed on citrus supplemented feed having citrus waste level as $0 \%, 2.5 \%, 5 \%, 7.5 \%$ and $10 \%$. The ingredients for preparation of nuggets were weighed and mixed according to the recipe (Table 1). The meat was washed with tap water, deboned manually and minced using electric mincer (MG 100). The broiler meat and onions were mixed in a meat mixer for five minutes, and then all other ingredients were added according to recipe and mixed using meat mixer to provide a uniform blend. The mixture was extended in a thin layer (10 $\mathrm{mm}$ thickness) and shaped into discs of $30 \mathrm{~mm}$ diameter $(50 \pm 1 \mathrm{~g} /$ piece $)$ to form a nugget. The nuggets were dipped in plain flour and bread crumbs separately and baked at $180^{\circ} \mathrm{C}$ till attaining the desire color and texture. The nuggets were also stored at $-20^{\circ} \mathrm{C}$ for further analysis for different parameters at 0,15 and 30 days of the storage. 
Table 1. Recipe of the nuggets prepared from the broiler's breast meat fed on the feed with addition of citrus waste

\begin{tabular}{c|c|c}
\hline Sr. No & Name of the ingredient & Quantity used \\
\hline 1 & Chicken boneless & $500 \mathrm{~g}$ \\
2 & Egg & 01 \\
3 & Black pepper & $12 \mathrm{~g}$ \\
4 & Garlic paste & $15 \mathrm{~g}$ \\
5 & Onion & $150 \mathrm{~g}$ \\
6 & Plain flour & $120 \mathrm{~g}$ \\
7 & Bread crumbs & $70 \mathrm{~g}$ \\
8 & Salt & $15 \mathrm{~g}$ \\
\hline
\end{tabular}

\section{Quality analysis of nuggets}

Color of the Nuggets was determined with the method described by El-Gasim and Al-Wesali (2000) using hunter lab color measurement device in AARI Faisalabad. The $\mathrm{pH}$ of the nuggets prepared with chicken meat was determined as described by Sallam et al. (2004). Water activity of meat nuggets was measured following the method of El-Gasim and Al-Wesali (2000) using combination of a ventilated humidity and temperature probe. The humidity and temperature probe automatically showed the water activity value when it was placed on the meat samples. Water holding capacity of broiler meat nuggets was determined according to the method of Qiao et al. (2001). The nuggets samples were placed in $11 \mathrm{~cm}$ diameter filter paper between Plexiglas plates and pressed at 2000 psi pressure for 1 minute. The water holding capacity was measured using formula as indicated in Eq. 1 .

Water Holding capacity $=\frac{100 \times(\text { total juice area }- \text { meat film area }) \times \text { water } / \text { squire inch filter paper }}{\text { Total moisture }(\mathrm{mg}) \text { of original sample }(\text { sample weight in }(\mathrm{mg}) \times \% \text { moisture })}($ Eq. 1$)$

Thiobarbituric acid reactive substances (TBARS) assay was measured following the method of Asghar et al. (1989). The per-oxidative reaction was initiated by adding ferrous sulphate and hydrogen peroxide to the nuggets samples held in a water bath at $37^{\circ} \mathrm{C}$. One mL sample prepared in buffer solution $(0.1 \mathrm{M} \mathrm{KCl}: 0.05 \mathrm{M} \mathrm{NaOH}$; $0.13 \mathrm{M}$ Lactic acid) with $\mathrm{pH}$ 5.3-5.4 was withdrawn at $30 \mathrm{~min}$ intervals for a period of $120 \mathrm{~min}$ and mixed to a same volume of solution of Thiobarbituric acid $(0.4 \%)$, trichloroacetic acid $(10 \%)$, and hydrochloric acid $(0.25 \mathrm{~N})$. The mixture was heated in a boiling water bath for $15 \mathrm{~min}$ and then cooled. After centrifugation, absorbance of supernatant was measured at $532 \mathrm{~nm}$. The extent of samples lipid peroxidation was calculated using the formula as indicated in $E q .2$.

$$
\mathrm{n}-\text { Moles of Malondialdehydes }=\frac{\text { (sample absorbance-blank }) \times \text { Total sample volume }}{0.00156 \times 1000(\text { per } \mathrm{mL})}(\text { Eq. } 2)
$$

The DPPH radical scavenging activity of broiler meat nuggets was determined following the method of Jung et al. (2010). The antioxidant activity of meat muscles fractions estimated by measuring scavenging abilities to DPPH stable radicals. A sample of $125 \mu \mathrm{L}$ was mixed with $0.0012 \mathrm{M} \mathrm{DPPH}$ solution followed by the addition of $95 \%$ $\mathrm{MeOH}$ up to final volume of $4 \mathrm{~mL}$. The absorbance of the resulting solution and the blank was recorded after $30 \mathrm{~min}$ at room temperature. The disappearance of DPPH was noted 
using spectrophotometer (CESIL CE7200, England) at $515 \mathrm{~nm}$. Inhibition of free radicals by DPPH in percent (\%) was calculated using formula as presented in Eq. 3 .

$$
\text { Inhibition }(\%)=[100 \times(\text { A blank-A sample }) \div \text { A blank }
$$

\section{Statistical analysis}

The data obtained from treatments and replications were subjected to statistical analysis using statistical program SAS version 9.0 to determine the level of significance by two-way factorial ANOVA and Least Significant Different test as described by Steel et al. (1997).

\section{Result and discussion}

\section{TBRAS of the nuggets}

TBARS is the standard to evaluate oxidation of meat and meat products. The higher value of TBARS shows that product is towards the oxidation. Figure la shows that the TBARS of chicken meat nuggets was significantly influence due to interaction effect of effect of treatment and storage. TBARS value of the nuggets reduced in the treatments $\left(\mathrm{MN}_{10}\right)$ of the nuggets which was prepared from the meat of the broilers that were fed on the feed with the higher levels of citrus supplemented feed and higher values of the TBARS were observed in the control treatment $\left(\mathrm{MN}_{0}\right)$ at storage of 30 days. However, the TBARS value of the nuggets increased with the storage time but this increase was minimum in the treatment which was made from the chicken meat which have higher antioxidants from the citrus waste. Sohaib et al. (2013) observed the quality of the nuggets which was made from the chicken meat that were fed on the feed with alpha lipoic acid and alpha tocopherol was higher as compared to the control treatment. He observed that the TBARS value of the nuggets was high in the control treatment and low on the treatment which were prepared from the meat which have higher level of alpha lipoic acid and alpha tocopherol. Divya and Singh (2013) investigated addition of bitter melon extract as a source of natural antioxidant in the chicken meat nuggets. It was observed that addition of bitter melon in the chicken nuggets at $1 \%$ level improved the antioxidant properties via TBARS of the nuggets and the nugget controlled more lipid oxidation with bitter guard as a source of antioxidant. Mishra et al. (2015) observed increased in the TBARS value of the dehydrated chicken meat balls stored at ambient temperature for 45 days and also decrease in the TBARS value was observed when treated meat with rice flour was used.

\section{DPPH activity}

The data for DPPH activity of the nuggets prepared with the broiler breast meat fed on the natural antioxidants from the citrus waste is presented in the Figure $1 b$ and Figure $1 c$, that shows nuggets have significant effects for DPPH activity due to treatments and storage life.

The mean values showed that maximum DPPH activity of nuggets was observed in $\mathrm{MN}_{10}$, which was prepared from meat of broilers that were fed on $10 \%$ citrus supplemented feed while minimum DPPH activity value was observed in $\mathrm{MN}_{0}$, the meat of that treatment was taken from the broilers group which were fed on control feed. This 
difference in the DPPH activity of different treatment is correlated with the amount of citrus waste used in the feed of broiler, as citrus waste is a rich source of phenolic substances like flavonoids which possess antioxidant activity and the natural antioxidants in the meat of the broilers raised DPPH activity. The DPPH activity of nuggets reduced during storage because of the loss in the polyphenolic contents of the meat.
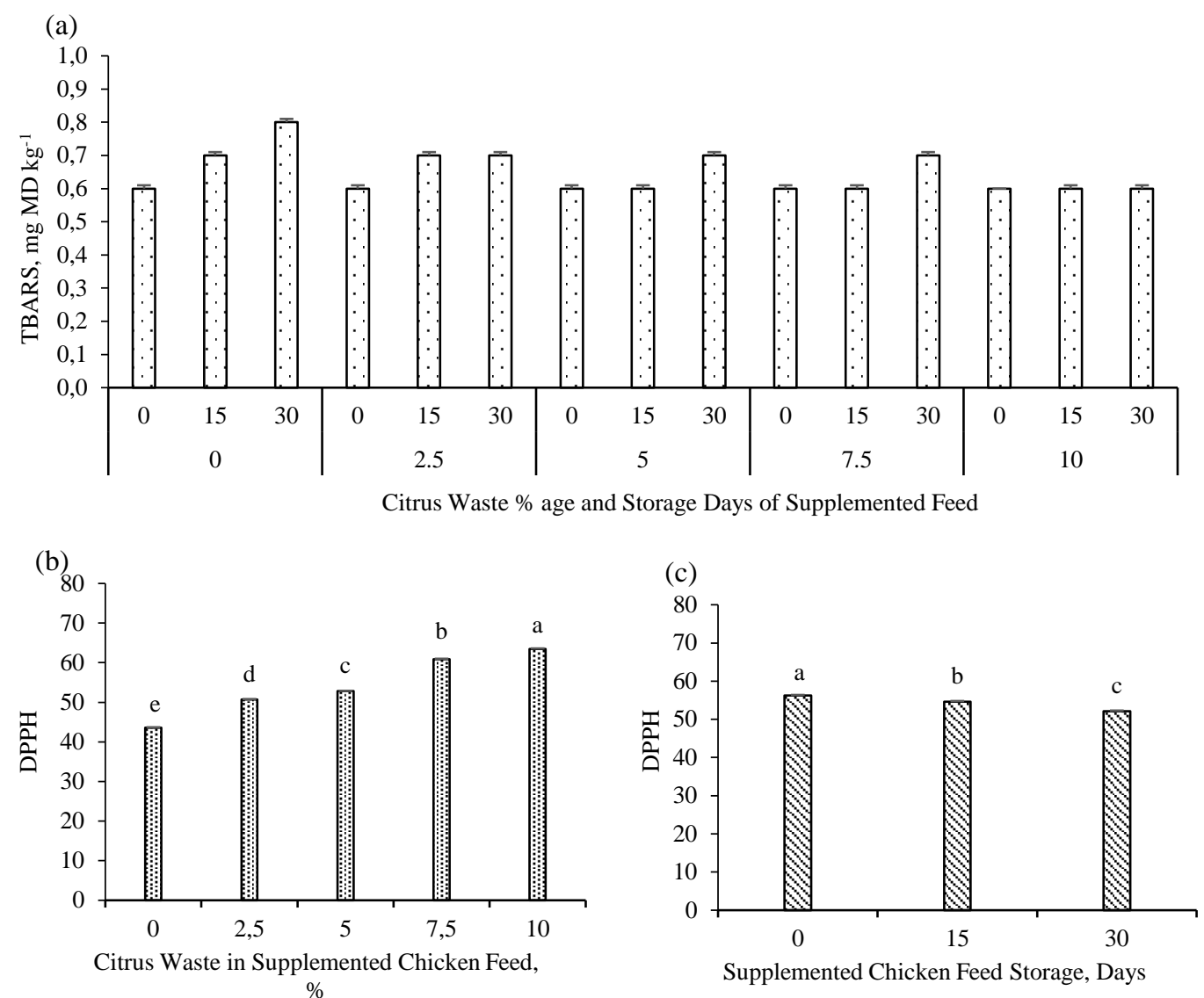

Figure 1. Interaction effect of citrus waste supplementation and storage on TBARS (a) and individual effect of citrus waste supplementation (b) and storage (b) on chicken meat nuggets

O'Sullivan et al. (2004) added different level of tocopherol acetate (vitamin E), rosemary $(0.10 \%)$, sage $(0.10 \%)$ and tea catechins $(0.01 \%)$ in the feed of the broilers and concluded that nuggets made from the breast meat of broilers fed on the vitamin $\mathrm{E}$ alone have better antioxidant activities as measured by DPPH activity. Maliluan et al. (2013) added rice bran instead of wheat flour by substitution method in the formulation of the chicken nuggets and observed that antioxidant activity of the nuggets enhanced when rice bran was added in the nuggets however the sensory qualities of the nuggets decreased by adding rice bran.

\section{pH of nuggets}

The data for $\mathrm{pH}$ of the nuggets prepared with the broiler breast meat fed on the natural antioxidants from the citrus waste is presented in the Figure 2, that shows that the nuggets have significant effects for treatments and storage life. $\mathrm{pH}$ value of the nuggets showed 
that maximum value of the $\mathrm{pH}$ was observed in the treatment which was made from the broiler meat which were fed on the control feed. Increased in the concentration of citrus waste in the feed of broiler decreased the $\mathrm{pH}$ of nuggets made from the broiler meat. $\mathrm{pH}$ value of nuggets increases as the storage period proceeded. Banerjee et al. (2012) prepared goat meat nuggets with broccoli powder extract as an antioxidant and observed decline in the $\mathrm{pH}$ of the nuggets when broccoli powder extract was used at the concentration of $2 \%$. Yadav and Sanyal (1999) reported that $\mathrm{pH}$ of the nuggets was increased when antioxidants were added in the nuggets and $\mathrm{pH}$ also increased with storage.

(a)

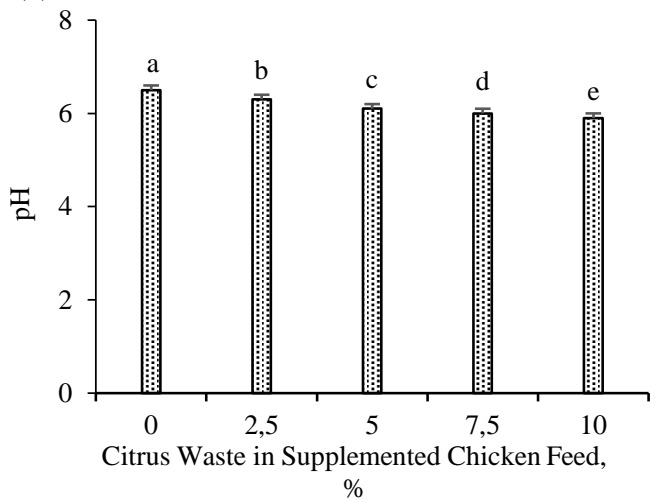

(b)

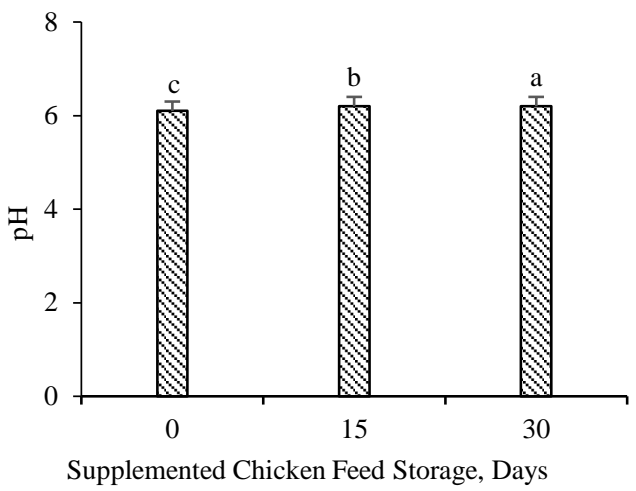

Figure 2. Effect of citrus waste supplementation (a) and storage (b) on pH of chicken meat nuggets

\section{Color of nuggets}

\section{Color $L^{*}$ value of nuggets}

The data for the color $\mathrm{L}^{*}$ value of the nuggets is presented in the Figure $3 a$, which shows that the significant effects for the color $\mathrm{L}^{*}$ value of the nuggets for treatments and storage was observed. The highest mean value (67.24) for color $\mathrm{L}^{*}$ of nuggets was observed for treatment prepared with the meat of broilers fed on treatment plan $\mathrm{MN}_{0}$ (control) which reduced significantly and lowest value of the color $\mathrm{L}^{*}$ value of the nuggets was observed for the treatments of nugget prepared from meat of broilers fed on $10 \%$ citrus waste supplemented feed $\left(\mathrm{MN}_{10}\right)$. It is evident from the results that increase in level of citrus waste supplementation in feed increase the natural compound deposition in meat leading to a reduced of color $\mathrm{L}^{*}$ value of nuggets. Decreasing trend for color $\mathrm{L}^{*}$ value of the broiler meat nugget from zero-day interval to 30 days' interval was observed.

Bosale et al. (2011) evaluated functional chicken nuggets for quality and sensory parameters. They also observed decrease in the color value of the nuggets when ground carrot and mashed sweet potatoes were used as a functional ingredient in the chicken nuggets, which support current investigations. Naveena et al. (2008) observed decline in color for broiler nuggets when they were stored at freezing temperature and color of the nuggets changed from red to brown which was due to the formation of metmyoglobin in broiler meat. O'Sullivan et al. (2004) found increase in the color $\mathrm{L}^{*}$ value of the chicken nuggets during storage when the meat of the broiler was used which was fed on Rosemary $(0.10 \%)$ as a natural antioxidant in the feed. 
(a)

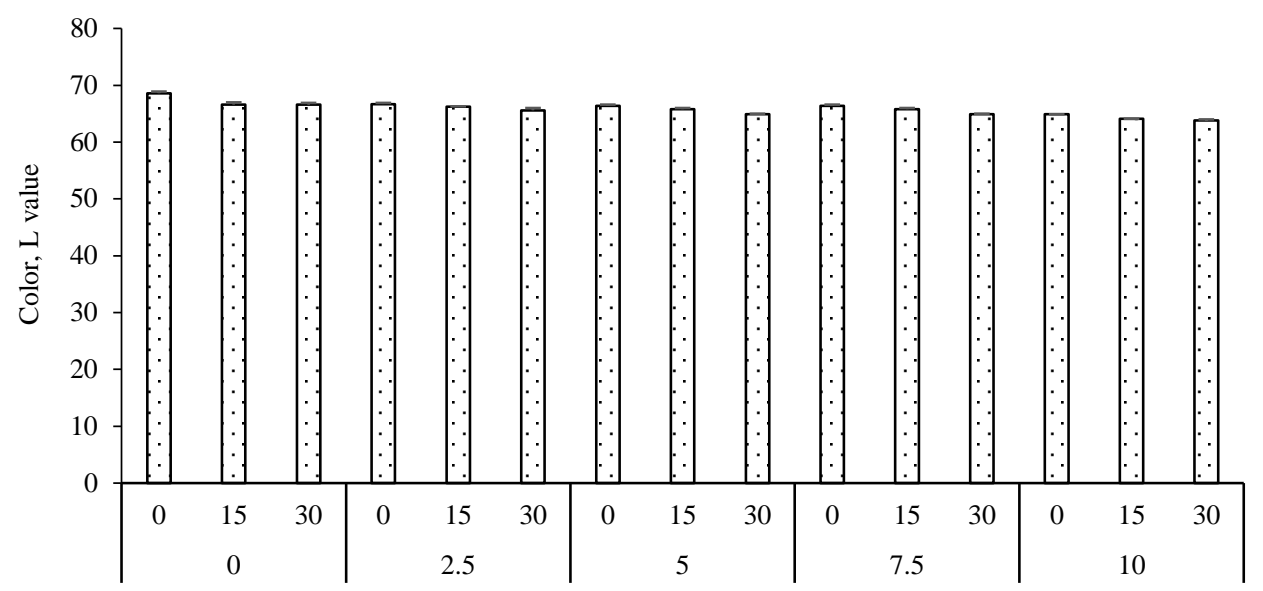

Citrus Waste \% age and Storage Days of Supplemented Feed

(b)

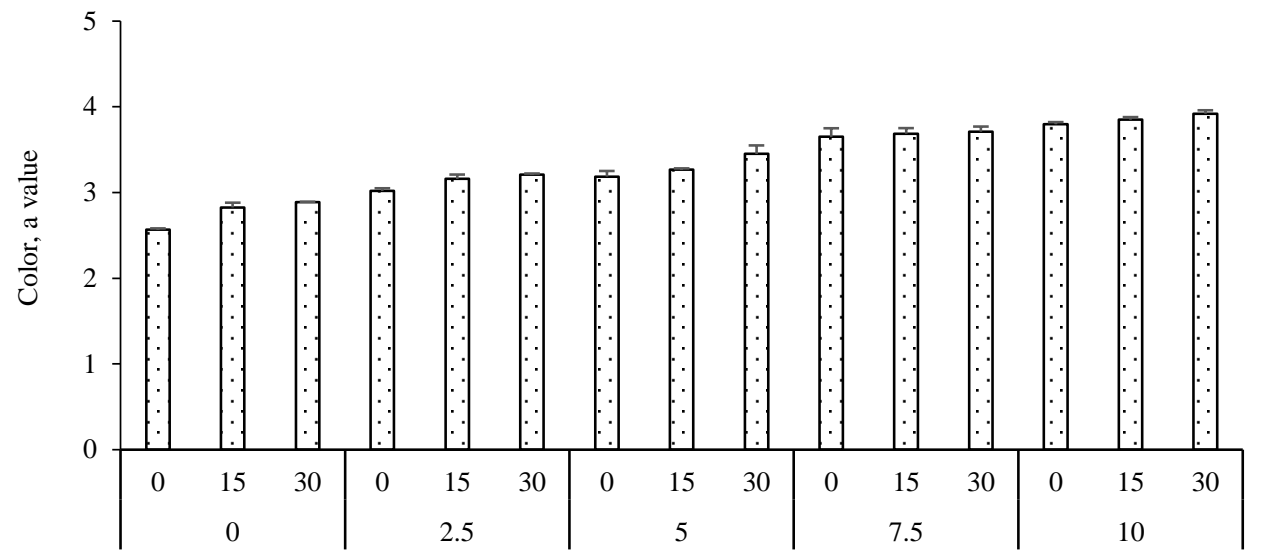

Citrus Waste \% age and Storage Days of Supplemented Feed

(c)

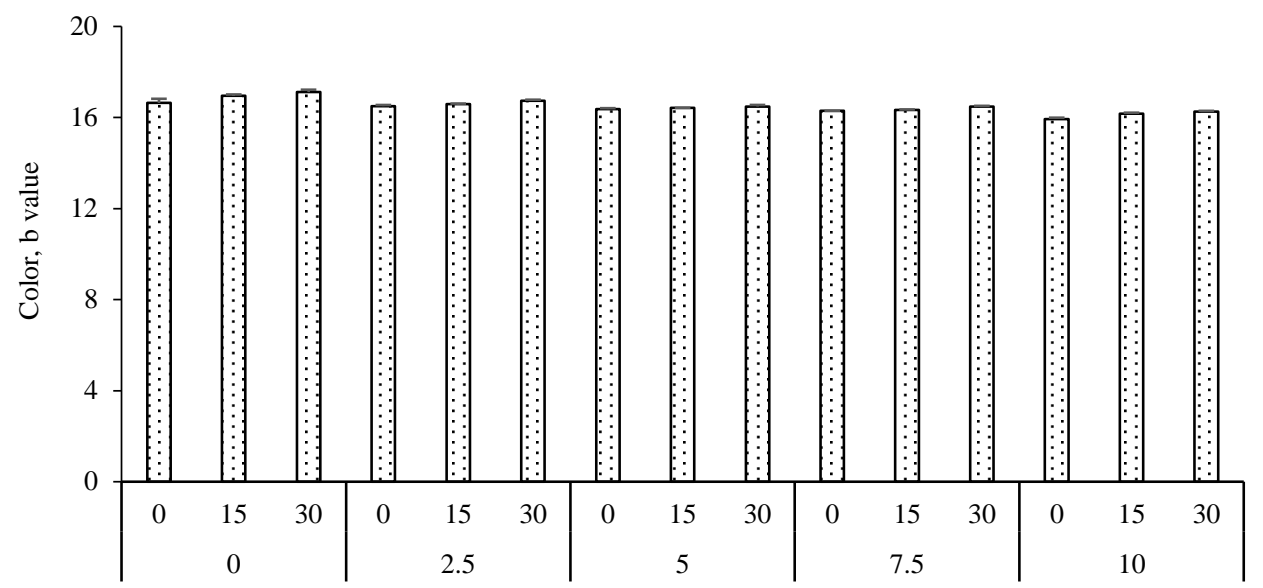

Citrus Waste \% age and Storage Days of Supplemented Feed

Figure 3. Interaction effect of citrus waste supplementation and storage on Color L value(a), a value (b) and $b$ value (c) of chicken meat nuggets 


\section{Color a* value (redness) of nuggets}

The data for the color a* value of the nuggets is presented in the Figure $3 b$, which shows significant effects for treatments and storage of the nuggets prepared from the broiler breast meat fed on the citrus waste supplemented feed. Maximum mean value for color $\mathrm{a}^{*}$ of nuggets was observed for $\mathrm{MN}_{10}$ which was prepared with the meat of the broilers which were fed on maximum citrus waste contents $(10 \%)$ whereas minimum mean value for color $\mathrm{a}^{*}$ values of nuggets was observed for $\mathrm{MN}_{0}$ which was prepared with the meat of the broilers which were fed on control feed ( $0 \%$ citrus waste). Similarly, potential variation was observed when the nuggets were stored for 30days under freezing conditions. Hunter $\mathrm{a}^{*}$ values of chicken nuggets containing natural antioxidants in the feed of the broiler was also found increase by O'Sullivan et al. (2004) in their studies, which support findings of the current studies. Verma et al. (2013) in their studies observed increase in the color $\mathrm{a}^{*}$ value of the sheep meat nuggets when they added guava powder in the nuggets.

\section{Color $b^{*}$ value (yellowness) of color of nuggets}

The data for the color $b^{*}$ value of the nuggets is presented in the Figure $3 c$, which shows significant effects for treatments and storage of the nuggets prepared from the broiler breast meat fed on the citrus waste supplemented feed. Maximum mean value for color $\mathrm{b}^{*}$ of nuggets was observed for $\mathrm{MN}_{0}$, the meat of which treatments was used from broilers that were reared on control feed ( $0 \%$ citrus waste in feed), whereas minimum value for $b^{*}$ values of color of nuggets was observed under $\mathrm{MN}_{10}$, the meat of which treatments was used from birds that were reared on feed with maximum citrus waste contents (10\% citrus waste in feed). The color $b^{*}$ value of the nuggets also increased as the storage period proceeded from 0 day to 30 days. Chandralekha et al. (2012) reported that chicken meat balls incorporated with pomegranate rind powder extract as a source of natural antioxidant, secured significantly higher color value than all other treatments but the color value decreased during storage. Similar results have been reported by Kala et al. (2007) in refrigerated chicken patties who observed increased in the color $b^{*}$ value.

\section{Texture (shear force) and water holding capacity of the nuggets}

The data for texture of the nuggets prepared with the broiler breast meat fed on the natural antioxidants from the citrus waste is presented in the Figure $4 a$ and $4 b$, which shows that the nuggets have significant effects for treatments and storage life. Maximum value for texture of the nuggets was observed after $30^{\text {th }}$ days of storage whereas minimum value for texture of nuggets was observed after 0 days' interval. Texture values for nuggets increased from 0 day to 30 days of the storage. The results of current investigations are in line with the studies of Ruiz-Ramirez et al. (2005) who concluded that texture become harder as the storage period of the nuggets proceeded. Moran et al. (2012) reported lower values for shear force in groups of the nuggets in which antioxidant was used as compared to the control groups.

The data for the water holding capacity of nuggets is presented in the Figure $4 c$, which shows significant interaction effect of treatments and storage on water holding capacity of nuggets prepared from the broiler breast meat fed on the citrus waste supplemented feed. The highest value of water holding capacity of nuggets was observed in $\mathrm{MN}_{10}$ (nuggets prepared from the breast meat of the broilers which were fed on $10 \%$ citrus waste supplemented feed) at 10 days of storage period while lowest was observed for $\mathrm{MN}_{0}$ 
(nuggets prepared from the breast meat of the broilers which were fed on control feed) at 0 days of storage. Water holding capacity of the nuggets increased as the storage time proceeded from 0 day to 30 days. Kikki et al. (2014) reported similar results in their studies, they worked on development of functional chicken nuggets with the addition of fermented bamboo shoots, beet root and cabbage. They observed that nuggets with the cabbage incorporation possesses higher score for water holding capacity. Golsuch and Alvarado (2010) observed increased in the water holding capacity of the broiler normal and pale breast fillet, when used different marinating techniques. However, Arun et al. (2008) working on the effects of full fat soy paste and textural soy protein on the quality and shelf life of the goat meat nuggets on freeze storage observed non-significant effects on the water holding capacity of the nuggets.
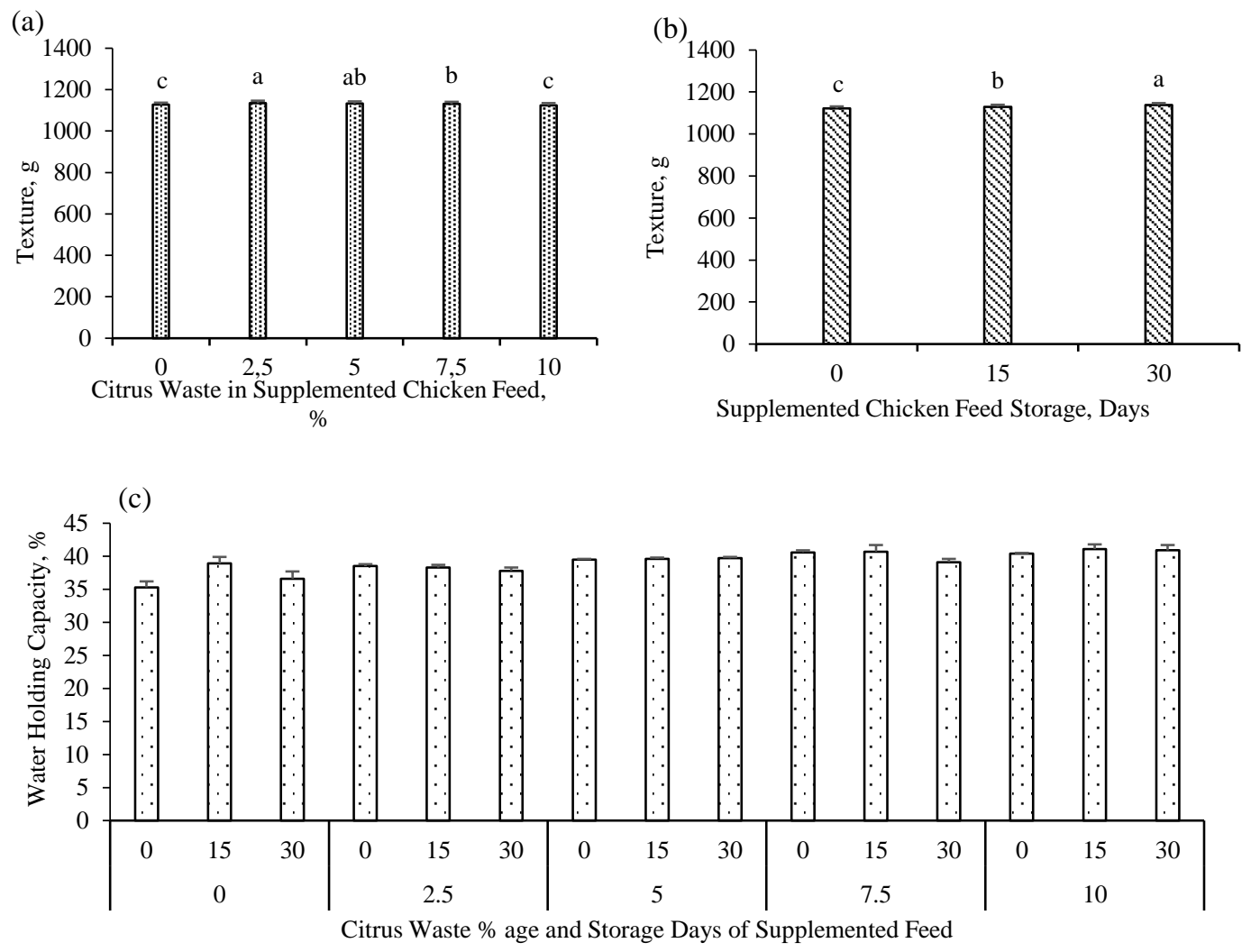

Figure 4. Individual effect of citrus waste treatment (a) and storage (b) on texture and interaction effect of treatment and storage on water holding capacity (c) of chicken meat nuggets

\section{Conclusion}

In the current findings citrus waste after juice extraction is used in the broiler meat production, the meat was further utilized in the nuggets preparation. The results showed positive effects on quality and the antioxidant profile of the nuggets. The citrus waste is normally wasted and in this study it is utilized for meat production. The study may be effective for the industry of food processing. Further studies might be conducted to increase utilization of citrus waste for different food products under different environmental conditions where different varieties of both citrus and the broiler chicken 
can be tried for manufacturing of meat, eggs, and meat products. In this way the citrus waste may be properly utilized for the benefits of human being as it is good source of natural antioxidants that is usually wasted after juice extraction.

Acknowledgement. The principal investigator of the project is grateful to Higher Education Commission of Pakistan for financial support for completion of this project.

\section{REFERENCES}

[1] Amaral, A. B., Marcondas, V. D., Suzana, C. D. S. L. (2018): Lipid oxidation in meat: mechanism and protective factors- A review. - Food Science and Technology Journal. DOI: http//doi.org.10.1590/fst32518.

[2] Arshad, M. S., Anjum, F. M., Asghar, A., Khan, M. I., Yasin, M., Shahid, M., El-Ghorab, A. H. (2011): Lipid stability and antioxidant profile of microsomal fraction of broiler meat enriched with alpha-lipoic acid and alpha-tocopherol acetate. - Journal of Agricultural and Food Chemistry 59: 7346-7352.

[3] Arshad, M., Nawaz, R., Ahmad, S., Qayyum, M. M. N., Ali, Z., Faiz, F., Manzoor, H. M. I. (2018): Morpho-nutritional response of lettuce (Lactuca sativa L.) to organic waste extracts grown under hydroponic condition. - Applied Ecology and Environmental Research 16(3): 3637-3648.

[4] Arun, K. D., Anjaneyulu, A. S. R., Gadekar, Y. P., Singh, R. P., Pragati, H. (2008): Effect of full-fat soy paste and textured soy granules on quality and shelf-life of goat meat nuggets in frozen storage. - Meat Science 80: 607-614.

[5] Asghar, A., Lin, C. F., Gray, G. I., Buckley, D. G., Booren, A. M., Flagel, C. J. (1989): Effect of dietary oil and alpha- tocopherol supplementation on membrane lipid stability of broiler meat. - Journal of Food Science 54(6).

[6] Banerjee, R., Verma, A. K., Das, A. K., Rajkumar, V., Shewalkar, A. A., Narkhede, H. P. (2012): Antioxidant effects of broccoli powder extract in goat meat nuggets. - Meat Science 91(2): 179-184.

[7] Bhosale, H. J., Sukalkar, S. R., Uzma, S. M. Z., Kadam, T. A. (2011): Production of xylanase by Streptomyces rameus grown on agricultural wastes. - Biotechnology 1(4): 505-512.

[8] Chandralekha, S., Babu, A. J., Moorthy, P. R. S., Karthikeyan, B. (2012): Studies on the effect of pomegranate rind powder extract as natural antioxidant in chicken meat balls during refrigerated storage. - Journal of Advanced Veterinary Research 2(2): 107-112.

[9] Cheng, J. H. (2016): Lipid oxidation in the meat. - Journal of Nutrition and Food Sciences 6(3).

[10] Divya, Singh, R. P. (2013): Effect of bitter melon as antioxidant in chicken nuggets. Indian Journal of Poultry Science 48(1): 63-67.

[11] El-Gasim, E. A., Al-Wesali, M. S. (2000): Water activity and Hunter color values of beef patties extended with Samh flour. - Food Chemistry 69(2): 181-185.

[12] Gorsuch, V., Alvarado, C. Z. (2010): Postrigor tumble marination strategies for improving color and water-holding capacity in normal and pale broiler breast fillets. - Poultry Science 89(5): 1002-1008.

[13] Jittrepotch, N., Ushio, H., Ohshima, T. (2006): Effects of EDTA and a combined use of nitrite and ascorbate on lipid oxidation in cooked Japanese sardine (Sardinopsmelanostictus) during refrigerated storage. - Food Chemistry 99(1): 70-82.

[14] Jung, S., Jun, H. C., Kim, B., Yun, H., Kruk, A. Z., Jo, C. (2010): Effect of dietary mixture of garlic acid and linoleic acid on antioxidative potential and quality of breast meat from broilers. - Meat Science 86(2): 520-526. 
[15] Kala, R. K., Kondaiah, N., Anjaneyulu, A. S. R., Thomas, R. (2007): Evaluation of quality of chicken emulsions stored at refrigeration for chicken patties. - International Journal of Food Science \& Technology 42(7): 842-857.

[16] Kikki, K., Diley, S., Sachdev, A. K., Biswas, A. K., Tyagi, P. K., Sen, A., Nath, A., Singh, M. (2014): Development of functional chicken nuggets incorporating functional bamboo shoots, beet roots and cabbage. - Indian Journal of Poultry Science 48(2): 257-260.

[17] Kumar, D., Tanwar, V. K. (2010): Effects of incorporation of ground mustard on quality attributes of chicken nuggets. - Journal of Food Science \& Technology 48(6): 759-762.

[18] Maliluan, C., Pramono, Y. B., Dwiloka, B. (2013): Chemical and the acceptability of chicken nuggets as functional food with utilization rice bran to substitute wheat flour. Jurnal Gizidan Pangan 4(1): 13-19.

[19] Miller, E. R., Pastor-Barriuso, R., Dalal, D., Riemersma, R. A., Appel, L. J. (2005): Metaanalysis: high-dosage vitamin $\mathrm{E}$ supplementation may increase all-cause mortality. Annals of Internal Medicine 42(1): 37-46.

[20] Mishra, B. P., Geeta, G., Sanjod, K. M., Prasana, K. R., Renuka, N. (2015): Storage stability of aerobically packaged extended dehydrated chicken meat rings at ambient temperature. - Turkish Journal of Veterinary and Animal Sciences 39(4): 493-500.

[21] Mohamed, A., Jamilah, B., Abbas, K. A., Rahman, A. R. (2008): A review on lipid oxidation of meat in active and modified atmosphere packaging and usage of some stabilizers. - Journal of Food, Agriculture and Environment 6(3): 76-81.

[22] Moron, L., Andres, S., Bodas, R., Prieto, N., Giraldez, F. J. (2012): Meat Texture and Antioxidant Status Are Improved When Carnosic Acid Is Included in the Diet of Fattening Lambs. - Meat Sci. 9: 430-434.

[23] Naveena, B. M., Sen, A. R., Vaithiyanathan, S., Babji, Y., Kondaiah, N. (2008): Chicken patties. - Meat Science 80(4): 1304-1308.

[24] O’sullivan, C. M., Lynch, A. M., Lynch, P. B., Buckley, D. J., Kerry, J. P. (2004): Use of antioxidants in chicken nuggets manufactured with and without the use of salt and/or Sodium Tripolyphosphate: Effects on product quality and shelf-life stability. International Journal of Poultry Science 3(5): 345-353.

[25] Prasetyo, M., Chia, M., Hughey, C., Were, L. M. (2008): Utilization of electron beam irradiated almond skin powder as a natural antioxidant in ground top round beef. - Journal of Food Science 73(1): 1-6.

[26] Qiao, M., Fletcher, D. L., Smith, D. P., Northcutt, J. K. (2001): The Effect of Broiler Breast Meat Color on $\mathrm{pH}$, Moisture, Water-Holding Capacity, and Emulsification Capacity. Poultry Science 80(5): 676-680.

[27] Ruiz-Ramirez, J., Serra, X., Arnau, J., Gou, P. (2005): Profiles of water content, water activity and texture in crusted dry-cured loin and in non-crusted dry-cured loin. - Meat Science 69(3): 519-525.

[28] Sallam, K. I., Ishioroshib, M., Samejima, K. (2004): Antioxidant and antimicrobial effects of garlic in chicken sausage. - Lebensmittel-Wissenschaft \& Technologie 37(8): 849-855.

[29] Sohaib, M., Anjum, F. M., Khan, M. I., Arshad, M. S., Yasin, M., Shahid, M. (2013): Effect of $\alpha$-Lipoic Acid and $\alpha$-Tocopherol Acetate Enriched Broiler Diet on Oxidative Stability and Quality of Broiler Leg Meat and Meat Products. - Journal of Food Processing and Technology 4(7): 1-7.

[30] Steel, R. G. D., Torrieand, J. H., Dicky, D. A. (1997): Principles and procedures of statistics. A biometrical approach. $-3^{\text {rd }}$ ed. McGraw Hill Book Co. Incorporations, New York.

[31] Verma, A. K., Rajkumar, V., Banargee, R., Biswas, S., Das, A. K. (2013): Guava (Psidiumguajava $\mathrm{L}$ ) powder as dietary antioxidant in the sheep meat nuggets. - AsianAustralasian Journal of Animal Sciences 26(6): 886-895.

[32] Yadav, P. L., Sanyal, M. K. (1999): Development of livestock products by combination preservation technique. - In: Proceedings of National Seminar on Food Preservation by Hurdle Technology and Related Areas, DFRL, Mysore, India: 104-109. 